\title{
Study of the Effects of Planned and Written Training on Anxiety in Neurosurgical Patients
}

\author{
Research Article
}

\section{Shahrzad Ghiasvandian ${ }^{1}$, Mohammad Taher ${ }^{2}$, Hojat Ghaffari ${ }^{3}$, Hadi Ahmadi Chenari ${ }^{*}$}

\begin{abstract}
1. Associate Professor, School of Nursing and Midwifery, Tehran University of Medical Sciences, Tehran, Iran 2. Ph.D Candidate in Nursing, School of Nursing and Midwifery, Tehran University of Medical Sciences, Tehran, Iran 3. BSc, Department of Nursing, Ferdows School of Health and Allied Medical Sciences, Birjand University of Medical Science. Birjand, Iran

4. Ph.D. candidate in nursing, School of Nursing and Midwifery, Tehran University of Medical Sciences, Tehran, Iran Faculty of Department of Nursing, Ferdows School of Health and Allied Medical Sciences,

Birjand University of Medical Sciences, Birjand, Iran
\end{abstract}

\begin{abstract}
Background \& Aim: Anxiety and depression are considered as important complications before surgery. Given the importance of reducing anxiety in patients nominated for surgery, different methods are conducted for this purpose, that patient training is one of these methods, this study was performed with the aim of influence of planned and written education on anxiety in patients scheduled for neurosurgery. Material and Methods: This study was an experimental that 90 neurosurgery patients were randomly divided into 3 groups of planned, written and control training. At the first stage, all patients responded to 40 questions of Spielberger anxiety questionnaire and then intervention was performed in the planned and written training groups. Then assessment of anxiety in patients after training was conducted in three groups. In order to analyze the data, in addition to calculate the mean and standard deviation, independent t-test and ANOVA were used. Results: The results showed that there is no difference between the average anxiety of patients before the training $(\mathrm{P}>0.05)$. But there is difference between patients anxiety in the three groups after the test $(\mathrm{P}<0.05)$. And by comparing the mean, it was shown that mean anxiety in two planned and written training groups is decreased after training. Conclusion: Given that nurses play an important role in the investigation and relief of patients anxiety, and compared to other members of the healthcare team spend more time with patients undergoing surgery, the planned training method must therefore be considered to provide effective support to reduce anxiety before surgery.
\end{abstract}

Keywords: Neurosurgical Patients, Written training, Planned training, Anxiety.

\section{Introduction}

Traffic accidents have been known around the world as the leading cause of disability and mortality and they are a major public health problem in developing and developed countries (1). According to the World Health Organization, by 2020, road traffic accidents will be the third leading cause of disease worldwide (2), so that approximately 10 million worldwide traffic accident occurs in a year, where 1.2 million people were killed and 20-50 million people are suffered disability (3). Traffic accident in Iran in terms of the number of victims, is the second leading cause of death and more than a third of the hospital beds in the country dedicated to the victims of traffic accidents. This is despite the fact that, on average, traffic accident is the world's ninth death cause. In developed countries, including America, the damage caused by trauma like vehicle crash, is the seventh leading cause of death (4).

*Corresponding Author:

Hadi Ahmadi Chenari

Phd candidate in Nursing,

School of Nursing and Midwifery,

Tehran University of Medical Sciences,

Tohid Sq. East Nostrat St, Iran

Email id: ahmadi.h@,bums.ac.ir
This issue increases direct costs (such as medical expenses resulting from accident and incident disability care) and indirect costs (such as psychological problems, including anxiety and depression in individuals and the loss of the labor force permanently or temporarily) (4). Anxiety is a surround, unpleasant and vague mode arousal with autonomic nervous system, headache, sweating, palpitations, chest muscles cramps, gastrointestinal discomfort and malaise (5). Anxiety has a negative effect on healing and tissue repair; In addition, too much mental and physical energy spent during the patient's anxiety can lead to fatigue and causes a series of biochemical activity in the body, which stimulates the autonomic system and muscle tension and increases the production of corticosteroids, and with stimulation of the sympathetic nervous system, leads to increased heart rate, increased blood pressure, decreased blood supply to the wound, arterial vasoconstriction and decreased partial pressure of tissues $(6,7)$. If anxiety is not controlled or become chronic, may result in increased proteolysis, reduced wound healing, increased risk of infection, the change in immune response and fluid and electrolyte imbalance and changes in sleep pattern (8). These factors cause prolonged hospitalization and delayed discharge for patients (9). Anxiety is divided into two groups of overt 
and covert, overt anxiety accession is situational and assigned to stressful positions (10), but covert anxiety implies individual differences in response to stressful situations with different levels of overt anxiety (11).

Anxiety control techniques include drug and nondrug methods. Based on studies of the drugs, benzodiazepines are effective in reducing anxiety, but on the one hand side effects of these drugs and on the other hand, their temporary effect have caused conducting research on non-pharmacological methods in recent years; Among these interventions, we have anxiety and pain adjustment by means of training (12).

Today, nurses use several methods in patient training that every one of these training methods may have different effects in controlling anxiety (12). Therefore, using training methods that can be useful in the adjustment of anxiety, is very important. Therefore, before providing necessary training to patients, decision making should be done about the appropriate training method (13). Accordingly, the present study has been designed and implemented to evaluate the effect of two training methods of written and planned on anxiety of traffic accidents patients.

\section{Material and Methods}

This study was an experimental study which was conducted in 2018 in Emam Reza Hospital of Birjand. Community of this study were neurosurgical patients. after reviewing patient records, patients including criteria for the study were randomly assigned to one of three groups of written, planned and control training groups. Inclusion criteria included an age range of 18 to 65 years, having read and write ability, no membership in the medical health care jobs, lack of chronic pain and lack of drug addiction and exclusion criteria included the patient's hemodynamic instability, do not consent to continue participating in the study.

Data collecting instruments included demographic information questionnaire and Spielberger anxiety questionnaire which this questionnaire consists of 40 items related to anxiety that the overall anxiety score is between 20 and 80 .

After informed consent was obtained, to the written group patients, Simple and understandable language pamphlet was given for study. For planned group, pamphlet and CD (includes film, power point, word) includes training contents based on the Herbart method and progress is from easy steps towards the more difficult ones, and educational materials was taught to the audience for staging (from easy to difficult). In planned group, each stage requires the active participation of the audience to fill in the blanks of a written, solve a problem and answer a question. The control group was given no training, and then anxiety questionnaire was completed in each three groups after training. After data collection and data entry, analysis using SPSS version 16, the mean and standard deviation, independent t-test and ANOVA were used.

\section{Results}

In this study 90 neurosurgery patients were randomly divided into 3 groups of planned, written and control training. Demographic characteristics of samples have shown in table 1.

Table 1. Demographic character istics of samples

\begin{tabular}{|c|c|c|c|}
\hline Variable & Components & Frequency & Percent \\
\hline \multirow{4}{*}{ Gender } & Female & 31 & 34.4 \\
\cline { 2 - 4 } & Man & 59 & 65.6 \\
\cline { 2 - 4 } & Total & 90 & 100.0 \\
\hline \multirow{4}{*}{ Level of Education } & Elementary & 49 & 54.4 \\
\cline { 2 - 4 } & High School & 34 & 37.8 \\
\cline { 2 - 4 } & Collegiate & 7 & 7.8 \\
\cline { 2 - 4 } & Total & 90 & 100.0 \\
\hline \multirow{4}{*}{ Habitat } & Urban & 48 & 53.3 \\
\cline { 2 - 4 } & Rural & 42 & 46.7 \\
\cline { 2 - 4 } & Total & 90 & 100.0 \\
\hline \multirow{5}{*}{ Employment status } & Working & 29 & 32.2 \\
\cline { 2 - 4 } & Employee & 4 & 4.4 \\
\cline { 2 - 4 } & housewife & 23 & 25.6 \\
\cline { 2 - 4 } & Self-employment & 15 & 16.7 \\
\cline { 2 - 4 } & Unemployed & 6 & 6.7 \\
\cline { 2 - 4 } & Students & 13 & 14.4 \\
\cline { 2 - 4 } & Total & 90 & 100.0 \\
\hline \multirow{5}{*}{ Marital status } & Married & 59 & 34.4 \\
\cline { 2 - 4 } & Single & 31 & 100.0 \\
\cline { 2 - 4 } & Total & 90 & \\
\cline { 2 - 4 } & & & \\
\hline
\end{tabular}


In this study, there is no difference between the mean anxiety of patients before training $(\mathrm{P}>0.05)$. But there is difference between the mean anxiety of patients in the three groups after training $(\mathrm{P}<0.05)$, and by comparing the mean, it was identified that mean anxiety in planned and written groups is reduced after training and shows the impact of this training on anxiety in patients (Table 2).

Table 2. The mean and standard deviation of total anxiety of patients before and after training in neurosurgery at three groups of participants

\begin{tabular}{|c|c|c|c|c|c|c|c|}
\hline \multirow{2}{*}{ Variable } & \multirow{2}{*}{ Components } & \multicolumn{2}{|c|}{$\begin{array}{l}\text { The pre-test total } \\
\text { anxiety }\end{array}$} & \multirow{2}{*}{ Significant } & \multicolumn{2}{|c|}{$\begin{array}{l}\text { The post-test total } \\
\text { anxiety }\end{array}$} & \multirow{2}{*}{ Significant } \\
\hline & & Mean & $\begin{array}{l}\text { Standard } \\
\text { deviation }\end{array}$ & & Mean & $\begin{array}{l}\text { Standard } \\
\text { deviation }\end{array}$ & \\
\hline \multirow{3}{*}{ Groups } & Control & 119.43 & 9.76 & \multirow{3}{*}{0.78} & 120.16 & 8.46 & \multirow{3}{*}{0.00} \\
\hline & Planned & 120.23 & 9.72 & & 99.33 & 9.18 & \\
\hline & Written & 121.16 & 9.28 & & 106.76 & 9.84 & \\
\hline
\end{tabular}

Results showed that there is a difference between mean differences of overt anxiety before and after training in neurosurgery at three groups of participants, $(p<0.05)$, and by comparing the averages of the three groups, it was found that overt anxiety of planned and written training group was less than the control group's (Table 3 ).

Table 3. Comparison of mean difference of overt anxiety before and after training in neurosurgery at three groups of participants

\begin{tabular}{|c|c|c|c|c|c|c|}
\hline Variable & Statistic & Total squares & df & $\begin{array}{c}\text { Mean } \\
\text { Squares }\end{array}$ & F & Significant \\
\hline \multirow{2}{*}{$\begin{array}{c}\text { Mean difference of overt } \\
\text { anxiety before and after }\end{array}$} & \begin{tabular}{c} 
Intergroup \\
\cline { 2 - 7 }
\end{tabular} & 4651.800 & 2 & 2325.900 & 102.937 & 0.00 \\
\cline { 2 - 7 } & Between & 1965.800 & 87 & 22.595 & & \\
\hline
\end{tabular}

Results showed that there is a difference between mean differences of covert anxiety before and after training in neurosurgery at three groups of participants, $(\mathrm{p}<0.05)$, and by comparing the averages of the three groups, it was found that covert anxiety of planned and written training group was less than the control group's (Table 4).

Table 4. Comparison of mean difference of covert anxiety before and after training in neurosurgery at three groups of participants

\begin{tabular}{|c|c|c|c|c|c|c|}
\hline Variable & Statistic & Total squares & df & Mean Squares & F & Significant \\
\hline \multirow{2}{*}{$\begin{array}{c}\text { Mean difference of cov- } \\
\text { ert anxiety before and } \\
\text { after }\end{array}$} & \begin{tabular}{c} 
Intergroup \\
\cline { 2 - 7 }
\end{tabular} & 324.689 & 2 & 162.344 & 6.972 & 0.00 \\
\cline { 2 - 7 } & Between & 2025.767 & 87 & 23.285 & & \\
\hline
\end{tabular}

\section{Discussion}

This study was performed to investigate the effect of planned and written training on anxiety patients of traffic accidents. Victims of traffic accidents are one of the main problems in the health system and impose high financial cost to it (14). One of the main problems of traffic victims in the hospital is anxiety. In most cases a sedative is used to control anxiety that has several side effects, while anxiety can be controlled with nonpharmacological methods. Findings from this study indicated that training methods cause reduced anxiety of victims of traffic accidents. Many studies have been done on the impact of training on anxiety. In a study titled "The effect of training intervention on anxiety of women waited for a mastectomy in Canada for intervention" Belleau et al. found that after the intervention, results have indicated that anxiety level of patients in the test group has been significantly 
$(\mathrm{P}<0.001)$ less than the anxiety level of control group (15). Also, the Morrell's study titled "Impact of structured training on anxiety level of patients before surgery in the list for cataract surgery" showed that training before surgery have significant impact in reducing the level of anxiety in patients undergoing cataract surgery $(\mathrm{P}<0.01)$, which is in line with the results of this study (16).

In a study Mousavi et al. has conducted using the Hospital Anxiety Depression Scale titled "The impact of face to face training and training manual in reducing depression and anxiety in adult patients before and after open heart surgery", training had could to improve the anxiety level greatly. In Mousavi's study in the intervention group, patients received face-to-face training and training manual at the same time training and the control group was given only the usual training, based on the obtained results, depression and anxiety after surgery had been reduced in both groups, that was statistically significant $(\mathrm{P}<0.04)(17)$.

In a study of Lin et al. were performed on 62 patients, titled "nursing interventions, pain and anxiety in patients undergoing abdominal surgery", they found that anxiety level of test group has been significantly reduced more than $90 \%$ after the intervention compared to the control group anxiety level $(\mathrm{P}<0.001)(18)$.

Patient education about the accident causes reduction in anxiety as a result of the adverse effects caused by it, therefore, we can consider patient training as an appropriate, effective and uncomplicated treatment and nursing care method, to control the level of anxiety in situations of tension and anxiety such as traffic accidents in individuals (19).

Anxiety access leads to a vicious cycle that leads to more severe levels of anxiety by stimulating sympathetic, muscle tension and increasing the production of corticosteroids $(20,21)$.

But unlike the aforementioned results, Deyirmenjian and colleagues in a study titled "Preoperative training for patients undergoing open heart surgery: a source of anxiety" in Beirut achieved borderline statistical difference between the experimental and control groups in terms of anxiety after surgery $(\mathrm{P}=0.08)(22)$.

Also, in Asilioglu and Celik's research conducted about the effect of preoperative training on anxiety in patients undergoing open heart surgery in Turkey, results showed a statistically significant difference between anxiety scores of test and control groups (23).

That is different with the results of this study and, it seems that, it is because factors such as age, sex, familiarity with non-pharmacological methods and other factors have impacts on changes in the level of anxiety, so the reason of the difference in the results and the results of this study may be a particular culture of sample population or collection tools or sampling method.

Consequently, based on the findings of this study and other similar studies, patient education is effective in reducing anxiety in patients with traffic accidents, because nurses play an important role in the investigation and relief of patients with anxiety and spend more time with patients compared to other health team members, so they should investigate this method.

\section{Acknowledgements}

The present study is the result of research project that has been approved by the research council of Birjand University of Medical Sciences. Authors would like to express special thanks of gratitude for supporting and providing found as well as we thank all Patients who participated in this research.

\section{Conflict of interest}

The authors have no conflict of interest disclosures to declare.

\section{References}

1. Garg N, Hyder AA. Exploring the relationship between development and road traffic injuries: a case study from India. Eur J Public Health 2006;16 (5):487-91.

2. T. B. Prehospital care of road traffic injuries in Chiang Mai. 2004; Available from: www:who.int/ world-health-day/2004/en/traffic facts en. Pdf.

3. Peden M. World report on road traffic injury prevention. Geneva: World Health Organization. 2004 Contract No. 10.

4. Birgani AG, Hakim A, Zare K. Epidemiologic study of fatal traffic accidents in Khouzestanprovincein in 2010. Scientific Journal of Rescue \& Relief. 2012;4 (2):28-35.

5. Sadock BJ, Sadock VA.Synopsis of psychiatry. 9th ed. Philadelphia: Lippincott Williams \& Wilkins; 2002.

6. Brunner LSH, Suddarth DS. Text book of medical surgical nursing: Critical thinking, ethical decision making and nursing process. Sami P, Translator 1th ed. Tehran: Boshra; 1995:48-49.

7. Barker R, Kober A, Hoerauf K, Latzke D, Adel S, Kain ZN, Wang SM. Out-of-hospital auricular acupressure in elder patients with hip fracture: a randomized double-blinded trial. Acad Emerg Med. 2006;13(1):19-23.

8. Phipps WJ, Monahan FD, Sands J, Marek JF, Neighbors M. Medical-surgical nursing: Health and illness perspectives. 7th ed. St. Louis: Mosby; 2003.

9. Agarwal A, Ranjan R, Dhiraaj S, Lakra A, Kumar M, Singh U. Acupressure for prevention of preoperative anxiety: a prospective, randomised, placebo controlled study. Anaesthesia. 2005; 60 (10):978-81.

10. Ghobarinabat B. Relationship between anxiety in parents with exceptional and normal chidren.Journal of Area and university. 2007;31:56-70.

11. Behdani F, Sargolzae MR, ghorbani E. Evaluation of life associated with depression and anxiety in students of Sabzevar. Journal of Sabzevar School of Medical of Sciences. 2000;7(2): 30-109.

12. Shureshi P, Ahmadi Chenari H, Ahmadi M, Jesmi A A. Effect of Education by Lecture and Pamphlet Methods on Soldiers Knowledge about Meningitis Disease. J Mil Med. 2015;17 (3):181-186.

13. Gholami H, Ahmadi chenari H, Chamanzari H, Shakeri M T. Amendable barriers in Clinical 
education from Viewpoints of students and clinical instructors at faculty of nursing and midwifery of Mashhad. Journal of Torbat Heydariyeh University of Medical Sciences. 2015;3 (1):34-29.

14. Gajalakshmi V, Peto R. Suicide rates in rural Tamil Nadu, South India: Verbal autopsy of 39000 deaths in 1997-1998. International Journal of Epidemiology. 2007;36:203-7.

15. Belleau FP, Hagan L, Masse B. Effects of an educational intervention on the anxiety of women awaiting mastectomies. Can Oncol Nurs J. 2001;11 (4):172-80.

16. Morrell G. Effect of structured preoperative teaching on anxiety levels of patients scheduled for cataract surgery. Insight. 2001;26(1):4-9.

17. Mosavi S, Sabzevari S, Abbaszadeh A, Hasannakhaee F. The effect of preparatory face to face education to reduce depression and anxiety in open heart surgery adult patient in Shafa hospital in Kerman. Iranian Journal of Nursing Research. 2008:29-38.

18. Lin LY, Wang RH. Abdominal surgery, pain and anxiety: preoperative nursing intervention. $\mathrm{J}$ Adv Nurs. 2005;51(3):252-60.
19. Davoudi M, Mohammadi Y, Yazdanparast E, Ahmadi Chenari H, Eslami H, Rajabi R et al. The effect of Multimedia Method of Education on Weight loss in Hemodialysis Patients. IJN. 2016;28 (98):31-38

20. Rohy G, Rahmany H, Abdollahy E, Mahmodi G. (Effect of music on preoperative anxiety and their physiological responses of patients). Boyye Gorgan University of Medical Science Journal. 2006;7(1):17 -21 .

21. Zakerimoghadam M, Aliasgharpoor M, Mehran A, MohammadiS.Effect of patient education about pain control on patients' anxiety prior to abdominal surgery. Journal of Faculty of Nursing \&Midwifery. 2010;15(4):13-22.

22. Deyirmenjian M, Karam N, Salameh P. Preoperative patient education for open-heart patients: a source of anxiety? Patient EducCouns. 2006;62(1):111-7.

23. Asilioglu K, Celik SS. The effect of preoperative education on anxiety of open cardiac surgery patients. Patient EducCouns. 2004;53(1):65-70. 